\title{
O fragmento de Galo
}

Fábio Paifer Cairolli

Universidade de São Paulo

cairolli@usp.br

ABSTRACT: The few remaining fragments from the works of the Latin poet Cornelius Gallus (c. 70-26 BC), discovered in Egypt in 1978, are presented, translated and analyzed in this paper. The role of these works among the books dated from the time of the poet, as well as some critical appreciation left by poets that lived during the Augustan reign and elected Cornelius Gallus as a model, are also brought into discussion. In addition, a poetic translation is also suggested.

KEYWORDS: Cornelius Gallus (c. 70-26 BC); epigram; elegy; poetic translation; elegiac couplet.

Uma das questões mais instigantes dos Estudos Clássicos atuais é a lacuna que a preservação irregular dos textos através dos tempos nos legou. Alguns dos grandes vultos da Antiguidade, por força do acaso ou do juízo que receberam através dos tempos, simplesmente se perderam, chegando a nós apenas o juízo daqueles que os puderam ler ou, algumas vezes, apenas seus nomes. É notável que determinados autores, como é o caso de Arquíloco, tenham sido sistematicamente preteridos, quando não censurados, pelos (e)leitores do período pré-imprensa.

Um capítulo à parte na história da filologia está representado pela contribuição, algumas vezes até romanesca, que os achados arqueológicos aportaram às letras antigas. Um dos exemplos mais famosos é o ressurgimento de Menandro (343/2 a.C. - 292/1 a.C.) através da descoberta de uma primeira comédia completa sua, o Misantropo (Dýskolos), em 1958. Esse autor, muito apreciado na Antiguidade, pôde ser novamente lido e conhecido, bem como confrontado a outras obras do seu gênero, dada a completude e relevância do novo texto.

Não foi este, contudo, o entusiasmo causado pela descoberta de um fragmento da obra do poeta latino Cornélio Galo (c. 69 a.C. - 26 a.C.), em 1978, nas escavações de Qasr Ibrim, na região sul do Egito. Os nove versos surgidos (referentes a três poemas diferentes, dos quais o segundo possui todos os versos íntegros) não impressionaram aqueles que esperavam algo digno da fortuna crítica desse poeta ${ }^{1}$ - poemas

\footnotetext{
${ }^{1}$ Cf. Sommerville, T. The literary merit of the new Gallus. Classical Philology. Chicago, vol. CIV, n. 1, p. 106-113, 2009.
} 
equiparáveis, por exemplo, à décima écloga de Virgílio, com a qual o mantuano o homenageia.

Tendo tais questões em vista, este artigo visa a apresentar o texto do fragmento de Galo aos leitores de língua portuguesa e, propondo leituras que melhor situem o seu mérito nas letras latinas, habilitar os fragmentos como representativos da auctoritas à qual estão ligados.

\section{Um famoso desconhecido}

Cornélio Galo é, possivelmente, o mais importante autor latino dentre aqueles que o tempo se encarregou de omitir. A maior prova de sua importância é o modo que os poetas da geração seguinte o referem como autoridade. ${ }^{2}$

A maior parte das informações que temos para traçar uma uita desse autor provém de Sérvio Honorato, comentador de Virgílio de fins da Antiguidade, a quem cedemos a voz para começar a discussão:

Gallus, ante omnes primus Aegypti praefectus, fuit poeta eximius; nam et Euphorionem, ut supra diximus, transtulit in latinum sermonem, et amorum suorum de Cytheride scripsit libros quattuor. Hic primo in amicitiis Augusti Caesaris fuit: postea cum uenisset in suspicionem, quod contra eum coniuraret, occisus est. Fuit autem amicus Vergilii adeo, ut quartus georgicorum a medio usque ad finem eius laudes teneret: quas postea iubente Augusto in Aristaei fabulam commutauit. Hic autem Gallus amauit Cytheridem meretricem, libertam Volumnii, quae, eo spreto, Antonium euntem ad Gallias est secuta.

Galo, antes de todos o primeiro prefeito do Egito, foi um poeta exímio, pois tanto traduziu Euforião para a língua latina, como acima dissemos, como também escreveu quatro livros sobre os seus amores por Cíteris. Este foi, primeiramente, amigo de César Augusto. Depois, como caiu em suspeição, porque conjuraram contra ele, matou-se. Era, além disso, amigo de Virgílio, que o louvava no quarto livro das Geórgicas, do meio até o fim. Este louvor, mandando Augusto, mudou para a fábula de Aristeu. Este Galo amava Cíteris, meretriz, liberta de Volúmnio, a qual, desprezando-o, seguiu Antônio, que ia para as Gálias. ${ }^{3}$

A esta passagem, acrescentamos outra, do mesmo autor, comentando agora o verso VI, 64 das Bucólicas de Virgílio:

\footnotetext{
${ }^{2}$ Cf. Prop. II 34, 91-92; Ov. Tr., IV 10, 53-54.

${ }^{3}$ Cf. Serv., in Buc. Virg. X, 1. As traduções aqui apresentadas, salvo indicação contrária, são de minha lavra. 
Helicon mons est Boeotiae, quae et Aonia dicitur. De hoc plurima cadunt flumina, inter quae etiam Permessus, iuxta quem dicit ambulantem Gallum ab una musa ad ceteras esse deductum et illic esse factum poetam. Qui elegos scripsit, qui a triumuiris praepositus fuit ad exigendos pecunias ab his municipiis, quorum agri in transpadana regione non diuidebantur.

Hélicon é um monte na Beócia, que é chamada Aônia. Dele, descem muitos rios, entre os quais o Permesso, próximo ao qual, diz [Virgílio], andava Galo, quando foi conduzido por uma Musa às demais e ali foi feito poeta. Escreveu elegias, foi preposto dos triúnviros para requerer dinheiro daqueles municípios na região transpadana cujos campos não foram divididos.

Essas duas passagens permitem que entrevejamos os principais eventos da vida deste autor: de origem humilde, ${ }^{4}$ afiliou-se à causa de Augusto provavelmente ainda durante o triunvirato - é o que nos deixa entrever Sérvio no segundo excerto. Seguramente manteve atividades que o relevaram na política ou que o favoreceram em relação a Augusto, pois, quando da derrubada de Cleópatra e Marco Antônio, foi escolhido para o governo da nova província, no Egito. Traído - a crer em Díon Cássio, ${ }^{5}$ o poeta espalhou estátuas suas e inscreveu seus feitos por todo o Egito, pelo que foi denunciado por um amigo -, matou-se.

No entanto, é notável que o comentarista mescle a vida do poeta com o que parece ser matéria de sua poesia. No comentário ao verso VI, 64 das Éclogas de Virgílio, descreve o que parece ser matéria de um poema prefacial de Galo ou de uma passagem descrevendo o momento em que foi feito poeta. Esses versos, aliás, devem ter-se tornado lugar-comum da poesia elegíaca, haja vista as narrações similares de Propércio (II 13, 1-8) e de Ovídio (Am. III, 1), nos quais a estada em lugar sagrado e na presença de Numes favoráveis converte o ego-elegiacus em poeta.

Igualmente se deve ler a narrativa dos amores de Galo por Cíteris: embora possa haver alguma veracidade no relato, seguramente o que está descrito ali é a matéria dos livros. A esse respeito, deve-se tomar a mesma precaução que tem sido recomendada aos leitores de Catulo e Propércio: retoricamente, a verossimilhança (ueri similis) tem a função de convencimento e comoção. Não deixa, contudo, de ser curioso notar que o mesmo Antônio que vence Galo na fábula é vencido na política por este, que o sucede na administração do Egito.

\footnotetext{
${ }^{4}$ Ao menos, assim o acusa Suetônio (Aug. LXVI), como que apontando a causa de sua traição à amizade de Augusto.

${ }^{5}$ Cf. Prop., Dion Hist. Rom. LIII 23, 5.
} 


\section{nuntius antiquus}

É de se crer que o processo que depôs o poeta e o conduziu ao suicídio tenha tido manobras escusas, haja vista o juízo moral que Díon Cássio faz no mesmo capítulo 23 do livro LIII da História Romana: aqueles que agiram contra Galo foram insinceros por bajulação a Valério Largo, amigo íntimo daquele e seu principal acusador, por causa do poder crescente que essa personagem estava adquirindo. Que o juízo da causa não tenha sido convincente, testemunha-o Ovídio, na elegia III, 9 dos Amores. ${ }^{6}$ A propósito da morte de Tibulo, o sulmonense nomeia aqueles que, praticantes do mesmo gênero de poesia, iriam recebê-lo no reino dos mortos:

Obuius huic uenias hedera iunenalia cinctus tempora cum Caluo, docte Catulle, tuo; tu quoque, si falsum est temerati crimen amici, sanguinis atque animae prodige Galle tuae.

Ao encontro deste [de Tibulo] virás, douto Catulo, cingidas de hera as têmporas juvenis, ao lado de teu Calvo. Tu também, Galo (se é que é falso o crime do amigo ultrajado), tu que és pródigo de teu sangue e de tua vida.

Embora esteja ainda sob o governo de Augusto (de cujo favor, aliás, Ovídio será abandonado), o poeta dos Pelignos indica que se acreditava ainda na inocência de Galo. Assim sendo, é relevante considerar a indicação de Sérvio sobre a existência de uma conjura, ou seja, um movimento mais ou menos estabelecido que logrou derrubá-lo, havendo ou não razão nas provas expostas.

Embora morto em dissidência com o principado, Galo teve sua auctoritas imediatamente reconhecida: é pouco posterior à sua morte a referência de Propércio, ${ }^{7}$ citando-o como uma das autoridades de poesia amorosa:

\section{Et modo formosa quam multa Lycoride Gallus mortuus inferna uulnera lauit aqua!}

E quantas feridas da formosa Licóris Galo lavou, morto, nas águas infernais!

A imagem nos faz supor que Galo, agora morto, reencontrou Licóris, no inferno. Propércio indica que Licóris já estava morta na ocasião do óbito do amante, e pode

\footnotetext{
${ }^{6}$ Cf. Ov., Am. III 9, 61-64.

${ }^{7}$ Cf. Prop. II 34, 91-92. 
significar que as feridas e a morte são matéria dos livros de Galo: se for assim, aí está o modelo que Propércio segue ao "matar" Cíntia, ao fim de seu terceiro livro.

Ovídio, pouco posterior aos dois poetas, é o que mais abertamente cita Galo como um de seus modelos. O motivo, ele mesmo o declara:

Quis poterit lecto durus discedere Gallo?

Quem é tão duro que consegue se afastar do leito de Galo? ${ }^{8}$

Da mesma forma que em Amores III 9, já citado, as referências de Ovídio relacionam-se à identificação das autoridades que segue. É o caso dos Tristes V 1, versos 15-18; aqui, contudo, a identificação é ao revés: informando que estas elegias não são amorosas, mas tristes, indica quais os autores daquela espécie:

Delicias siquis lasciuaque carmina quaerit, praemoneo, non est scripta quod ista legat. Aptior huic Gallus blandique Propertius oris, aptior, ingenium come, Tibullus erit.

Se alguém busca delícias e poemas lascivos, advirto, não são estes os escritos que deves ler. Mais apto, para este, é Galo e Propércio de voz leve; mais apto - orna o engenho - será Tibulo.

Também nos Tristes (II 1, 445-60), a lista dos antecedentes em poesia amorosa inclui Galo:

\section{Non fuit opprobrio celebrasse Lycorida Gallo, sed linguam nimio non tenuisse mero.}

Não foi opróbrio a Galo celebrar Licóris, mas a língua não abrandava com excessivo vinho.

E, por fim, a mais famosa e clara citação de Ovídio a respeito das autoridades do gênero elegíaco, Tristes IV 10, 53-4, em que alinha os praticantes do gênero, desde o fundador, Galo, até ele mesmo:

Successor fuit hic tibi, Galle, Propertius illi; quartus ab his serie temporis ipse fui.

\footnotetext{
${ }^{8}$ Cf. Ov., Rem. Am., 765.
} 
Este [Tibulo] foi teu sucessor, Galo, e Propércio o dele. Eu mesmo fui o quarto na série do tempo.

Este é o pinax da poesia elegíaca que será ecoado pelos tempos, como ocorre, um século depois, em Marcial:

Instanti, quo nec sincerior alter habetur pectore nec niuea simplicitate prior,

si dare uis nostrae uires animosque Thaliae et uictura petis carmina, da quod amem.

Cynthia te uatem fecit, lasciue Properti; ingenium Galli pulchra Lycoris erat; fama est arguti Nemesis formosa Tibulli; Lesbia dictauit, docte Catulle, tibi: non me Paeligni nec spernet Mantua uatem, si qua Corinna mihi, si quis Alexis erit.

Instancio (não existe peito mais sincero, nem em simplicidade mais perfeito), se queres dar à nossa Talia força e ânimo - pedes um canto imortal - dá-me o amor!

Cíntia te fez poeta, lascivo Propércio; para Galo, em Licóris 'tava o engenho; Nêmese fez, formosa, a fama de Tibulo; Lésbia, douto Catulo, te ditou:

os Pelignos e Mântua não me negam vate se eu tiver um Aléxis ou Corina.

\section{Uma leitura dos fragmentos}

Os fragmentos que retiraram Cornélio Galo do esquecimento foram encontrados no ano de 1978 no sítio arqueológico de Qasr Ibrim, no Egito. Os cinco pedaços de papiro que compõem o fragmento foram achados entre restos pertencentes ao século I a.C. e inícios do século I d.C. Embora a equipe que descobriu os fragmentos tenha sido bem prudente em relação à datação, ${ }^{9}$ a presença de uma moeda de Cleópatra VII, sem data, e de uma carta datada do nono ano de César (Augusto, isto é, 22/ 21 a.C.) permitem apontar que o documento estava na localidade na terceira década a.C. Esse período se inicia por uma expedição enviada (29 a.C.) pelo próprio prefeito Cornélio Galo àquela região fronteiriça, na qual guarnições são mantidas pelo menos até a paz celebrada entre Augusto e os etíopes no ano de 21/ 20 a.C.

\footnotetext{
${ }^{9}$ Cf. Anderson, R. et alii. Elegiacs by Gallus from Qasr Ibrim. Journal of Roman Studies. Cambridge, vol. LXIX, p. 127, 1979.

6
} 


\section{nuntius antiquus}

O papiro, catalogado sob o número 78-03-11, contém nove versos, separados por espaços em três grupos, editados da seguinte forma: ${ }^{10}$

tristia nequit[ia ... . ] a Lycori tua

Fata mihi, Caesar, tum erunt mea dulcia, quom tu maxima Romanae pars eri $<s>$ historiae, postque tuum reditum multorum templa deorum fixa legam spolieis deiuitiora tueis.

..... . .... tandem fecerunt c [ar]mina Musae quae possim domina deicere digna mea. .......... J. atur idem tibi, non ego, Visce .. . ....... l. Kato, iudice te uereor.

O primeiro grupo é composto por um único verso, lacunar, no qual se menciona Licóris no caso vocativo, isto é, a personagem é receptora deste poema. O segundo grupo, de quatro versos, é o mais bem preservado, não permanecendo nenhuma lacuna. O terceiro grupo, também de quatro versos, contém lacunas nos v. 1, 3 e 4; apesar disso, é possível reter o sentido geral do poema.

Vejamos a sua tradução:

Triste [....... Licóris, com as tuas malícias.

Meu fado, César, doce será então, quando tu fores a maior parte da história romana e, depois da tua volta, eu ler que os templos de muitos deuses estão mais ricos com os teus espólios pendurados.

$[\ldots \ldots \ldots \ldots$ enfim, as Musas fizeram canções que eu possa oferecer, dignas da minha senhora. [. . . . . . . ]ado o mesmo a ti, Visco, eu não $[\ldots \ldots \ldots \ldots]$, Catão, temo o teu juízo.

As principais causas da frustração causada pelo texto são características possivelmente vistas como deletérias, ou contrárias à melhor prática dos poetas antigos, tais como o uso de vocabulário prosaico (historiae, reditum), rimas e aliterações (domina deicere digna; post tuum reditum), a simplicidade (aparente) dos versos e a dificuldade em compreender a relação entre a matéria de cada um dos poemas.

A nosso ver, uma parte das dificuldades suscitadas pelos poemas pode ser diminuída se abordada em uma perspectiva dos gêneros. Anderson, Parsons e Nisbet

${ }^{10}$ Cf. Anderson, op. cit., p. 140. 


\section{nuntius antiquus}

(1979) afirmam com mais tranquilidade que os poemas em questão são epigramas; não se alongam, contudo, na compreensão do que esta definição pode implicar para os fragmentos em questão, detendo-se mais na tentativa de compreender a relação entre os poemas e a sua inclusão em um livro de elegias. ${ }^{11}$ Fairweather, rejeitando a primeira leitura, argumenta que "o que o papiro de Galo apresenta é o fragmento de um canto amebeu", ${ }^{12}$ alinhando os versos de Qasr Ibrim à poesia bucólica de Teócrito e Virgílio. Nos dois casos, nota-se que não há descura em relação à tradição interpretativa virgiliana que, de todas as formas, é a que até então melhor subsidiara as especulações sobre a poesia de Galo.

Assumir que os presentes versos são epigramas elimina a dificuldade de encontrar as conexões temáticas entre os poemas que, além de tudo, são verificáveis apenas no nível lexical. Essas relações lexicais não provam que os poemas possuem qualquer tipo de continuidade, mas atestam o engenho de Galo de alinhar poemas díspares pelo contraste semântico - o que, lembra Anderson, ${ }^{13}$ pode ser verificado em seu pentâmetro já conhecido (uno tellures diuidit amne duas).

O principal argumento a favor dessa desconexão pode ser encontrado, por exemplo, nas abundantes desconexões nos livros de Marcial. No quinto livro, por exemplo, veja-se o que reúnem os poemas 3, 4 e 5: em 3, Domiciano recebe Degis, líder dácio, que provoca inveja em seu irmão, pois este venera o imperador de longe, desde a província recém-dominada; em 4, Mirtale é uma bebedora contumaz que mistura folhas de louro ao vinho para disfarçar o hálito; em 5, Marcial se dirige a Sexto, bibliotecário imperial, aconselhando-o a guardar seu livro junto aos epigramatistas Catulo, Pedão e Marso.

Nos referidos poemas, a campanha militar envolvendo um César, o comportamento inadequado de uma mulher e o juízo a respeito de uma obra constituída são temas justapostos sem que isso implique conexões ou que se desprestigie o ingenium do poeta em questão, visto que, para os livros de epigramas de Marcial (que possivelmente se baseou em seus antecessores e provavelmente influenciou os que vieram depois), compostos por mais ou menos cem poemas, a uariatio, mistura de

${ }^{11}$ Cf. Anderson, op. cit., p. 149: The surviving epigrams seem to have been composed as a sequence dealing in turn with the ruling passions and dominating personalities of the poet's life.

${ }^{12}$ Cf. Fairweather, J. The "Gallus Papyrus": a new interpretation. The Classical Quarterly. Cambridge, vol. XXXIV, n. 1, p. 167, 1984: (...) what the "Gallus papyrus" presents is a fragment of an amoebaean song-contest.

${ }^{13}$ Cf. Anderson, op. cit., p. 149. 


\section{nuntius antiquus}

diversos assuntos, evita o cansaço. ${ }^{14}$ Há em Marcial diversos exemplos de epigramas que se leem melhor quando confrontados aos que lhe são próximos. Isso, contudo, não implica que haja relação entre quaisquer dois poemas, como quer parecer-nos que não há nos sobreviventes poemas de Galo.

É relevante notar aqui que a matéria desses epigramas de Galo é decorosa e frequente no gênero epigramático e que há, em Marcial, epigramas equivalentes aos que foram descobertos.

No primeiro fragmento, o termo epigramático mais evidente é nequitia, termo de difícil tradução, que pode designar tanto a travessura de uma criança e o dolo quanto a malícia e a devassidão de uma domina, senhora de um amante elegíaco. Não pretendemos aqui que se dispute a precedência do vocábulo no epigrama em relação à elegia, mas sim notar a forma como se insere naquele gênero. $\mathrm{O}$ termo ocorre nove vezes em Marcial, designando desde as brincadeiras de uma casta cadelinha até o comportamento sexual mais obsceno. Importa mostrar que essa palavra designa a matéria dos epigramas, como em VI 82, 3-5:

"Tune es, tune" ait" ille Martialis,

Cuius nequitias iocosque nouit,

Aurem qui modo non habet Batauam?”

"Tu não és, tu não és", disse, "aquele Marcial cujas lascívias $e$ gracejos são conhecidos por aquele que não tem um ouvido batavo?" (grifo meu)

e também o comportamento sexual de uma puella, em IX 67, 1-2:

\section{Lasciuam tota possedi nocte puellam, Cuius nequitias uincere nemo potest.}

Por toda a noite possuí uma menina lasciva, cuja devassidão ninguém pode vencer.

Neste poema, a nequitia é o atributo da menina lasciva, da mesma forma que no primeiro fragmento de Galo, mas usufruir de sua ousadia não desdoura ao poeta, que

\footnotetext{
${ }^{14}$ Cf. Mart. VIII, Praef. A respeito da variação para o livro de epigramas, cf. capítulo 2e, "A disposição no gênero epigramático", de nossa dissertação de mestrado, Pequena gramática poética de Marcial. (São Paulo: DLCV/ FFLCH-USP, 2009, p. 51-56). Concordam com a importância da variação outros dois autores de epigramas, Plínio, o Jovem (IV 14, 3), e Ausônio (epig. 2).
} 


\section{nuntius antiquus}

ainda afirma que a teve pura (v. 7: mihi pura fuit). Assumir que necessariamente o poeta está reprovando o comportamento de Licóris (o que é tentador por causa da palavra tristia) é pretender que em seus versos cantasse somente a exclusão amorosa, e não encontros como o que descrevem, além de Marcial, Catulo (32) ou Ovídio (Amores I, 5).

O segundo poema, por ser o mais íntegro, é o que causou maiores desencantos. Embora Fairweather com justiça indique que as deficiências pertencem ao campo da opinião, é redutora sua hipótese de que os versos tenham sido deliberadamente mal escritos com o intuito de demonstrar a falha do poeta que perderá o certame poético (o que assemelharia o fragmento à sétima écloga de Virgílio). Dito dessa forma, ignora-se que do ponto de vista da matéria esse é um epigrama encomiástico, semelhante a diversos que escreve Marcial para comentar os feitos do imperador.

Particularmente, a relação entre a felicidade dos súditos e os feitos do governante deriva da percepção de que o poder, no Império, não é uma força de atuação unilateral, mas uma complexa malha de relações e favorecimentos (nomeados em suas diferentes nuanças pelos abrangentes termos de patronato e clientelismo) em que a alta investidura de um indivíduo governante (o imperador, no caso, mas também outros mandatários) é sustentada pelos governados, a quem aquele confirma sua grandeza por meio do munus, o prêmio. Esse pode ser tanto a presença física do imperador após uma guerra ou seus atos de piedade, como nos versos de Galo, tanto quanto o oferecimento de prédios públicos ou espetáculos na arena. ${ }^{15}$ Essa forma de se relacionar politicamente fica mais clara no epigrama VIII 80 de Marcial:

\footnotetext{
Sanctorum nobis miracula reddis auorum nec pateris, Caesar, saecula cana mori, cum ueteres Latiae ritus renouantur harenae et pugnat uirtus simpliciore manu. Sic priscis seruatur honos te praeside templis et casa tam culto sub Ioue numen habet; sic noua dum condis, reuocas, Auguste, priora: debentur quae sunt quaeque fuere tibi.
}

Restituis o milagre de avós veneráveis, César, morrer não deixas velhos tempos,

\footnotetext{
${ }^{15}$ Sobre estas relações de poder em Roma, cf. Foucault, M. Microfísica do poder (acessado em 5 de julho de 2006, em <http://www.unb.br/fe/tef/filoesco/foucault/microfisica.pdf >). Cf. também Veyne, P. (org.). História da vida privada. Vol. I: do Império Romano ao ano mil. São Paulo: Companhia das Letras, 2009, p. 93-111. 
ao renovar-se à ausônia arena antigos ritos e com mais pura mão pugnar coragem.

Governas e nos priscos templos dura a honra, e sob Jove a cabana tem um nume.

Assim, fundando o novo, Augusto, o antigo trazes: tudo que foi e que é se deve a ti.

Aqui, a reintrodução do mos maiorum, dos antigos jogos e ritos é o munus de Domiciano: se, como diz Marcial no verso 8, tudo isso é devido ao imperador, quer dizer que foi por este empreendido para os imperadores, como uma nova fundação de Roma. Esse apelo ecoa a formulação de Galo de que a guerra e os despojos farão de César (sendo até pouco relevante se se trata de Júlio César ou de Otaviano) "a maior parte da história de Roma". É importante não desprezar a presença de historiae como termo técnico da Retórica: nessa passagem, não só Galo estará ajudando a construir a imagem que fará de César a mais elevada parte da história de Roma, como também ele passará a assumir o discurso historiográfico, por que vai relatar as causas dessa importância, e monumental, por utilizar o epigrama em sua função memorialística.

É sob esse critério que deverá ser lido o dístico que vem imediatamente depois de historiae. A construção post tuum reditum ("depois da tua volta", v. 4), que não passou despercebida aos olhos dos pesquisadores que se detiveram sobre o poema, ecoa passagens do Res Gestae Diui Augusti, documento tanto historiográfico quanto epigráfico, tais como post eius mortem ("depois da morte dele”, XXVII), post id tempus ("depois daquele tempo", XXXIV) e a mais interessante, pro reditu meo aram consacrare ("consagrar um altar pela minha volta"), que ocorre duas vezes, em XI e XII. Com isso, legam ("lerei”) adquire especial sentido, pois, mais importante que presenciar, Galo lerá sobre a guerra, quer no templo, numa epígrafe ou, mais propriamente, num livro de História - perpétua confirmação do poder que ganhará a guerra.

Dentre os três poemas que integram o fragmento, o terceiro é o que apresenta menos problemas de interpretação. O juízo literário (crisis, iudicium) é matéria abrangente, abundante tanto no gênero epigramático quanto no elegíaco. É de particular interesse, neste caso, a noção de não temer o juízo (non uereor, v. 9), que o aproxima do poema 116 de Catulo. No referido epigrama, ego-Catullus pretende evitar o confronto com Gélio, personagem desconhecida, por meio do envio de poemas de Calímaco (a lembrar-se, o juiz por excelência nas letras gregas, autor dos Pinakes, o maior catálogo 
de autores até então existente), mas, tendo sido atacado, se defende com as armas calimaquianas, isto é, os epigramas com que ataca aquela personagem (na coleção que chegou aos nossos dias, poemas 74, 80, 88-91), chamados tela, lanças. Em que pese à dificuldade causada pelas lacunas dos dois últimos versos do poema de Galo, o sentido geral parece não aportar novidades temáticas.

Pelo que até aqui temos visto, os três poemas de que se compõe o fragmento não são espécimes poéticas de difícil compreensão, mas poemas que integram o vasto campo temático do gênero epigramático, passíveis de relação com autores anteriores, tais como Catulo e, por extensão, Calímaco, e posteriores, como Marcial. Essa concepção entra em confronto com a tradição, que atribui fama a Galo por poemas elegíacos em que canta seu amor por Licóris, sem mencionar que pudesse ter escrito também epigramáticos. O que se vê nesse fragmento, se for representativo do total da coleção em que estava inserido, ajuda a compreender a relação da elegia erótica do principado com o gênero epigramático. ${ }^{16}$

No período em que Galo vive, a produção de epigramas de temática erótica já está estabelecida, quer em grego, quer em latim. Pelo menos desde o século IV a.C., os poetas que circulam ao redor da Biblioteca de Alexandria se detêm, de forma mais ou menos sistemática, sobre essa matéria, cujos exemplares chegarão ao nosso tempo particularmente nos volumes V e XII da Antologia Palatina. Estes serão os casos de Calímaco, Posidipo, Filodemo, Asclepíades e Dioscórides, por exemplo. Em Roma, esse gênero também está de alguma forma estabelecido, como se pode perceber pela sobrevivência de epigramas do fim do século II a.C., particularmente os de Lutácio Catulo, Valério Edítuo e Pórcio Licino, integrantes da espécie erótica.

Isso posto, pode-se entender a elegia erótica romana como continuação dos epigramas eróticos, em voga desde antes do principado. Não está claro em que ponto e de que modo a matéria abundantemente empregada nos poucos dísticos do epigrama foi utilizada no também antigo gênero elegíaco. Poetas elegíacos eróticos como Propércio e

\footnotetext{
${ }^{16}$ Conforme indica Gentili, não é fácil separar elegia de epigrama, nem os gêneros são rigorosamente classificados pelos leitores antigos. "Elegia", muitas vezes, indica apenas um esquema métrico, não o gênero literário ao qual se relacionam nomes tão antigos quanto os de Arquíloco e Mimnermo (séc. VI a.C.), assim como "epigrama", antes do gênero literário, se refere às inscrições lapidares de onde o gênero tirou a sua principal característica, a brevidade, e sua primeira matéria, a memória dos mortos. Assim, importa notar que, ao dizer elegia, um autor menos cuidadoso poderia incluir o civismo de Sólon e a acuidade de Marcial em um mesmo grupo, pelo critério do metro (Gentili, B. Epigramma ed elegia. In: DIHLE, A. (org.). L'Épigramme grecque. Entretiens sur Antiquité Classique. Genève: Vandroevres, 1968. Tome XIV, p. 39ss.). A ambiguidade vai-se dissolvendo com o desenvolvimento dos gêneros em questão, mas ainda em Plutarco (séc. II d.C.) há dubiedade no uso dessa terminologia.
} 


\section{nuntius antiquus}

Ovídio apreciam o trabalho de Galo da mesma forma que o de Catulo, autor que, sabemos, divulgou amores tanto epigramáticos quanto elegíacos. O mesmo Propércio inclui entre seus modelos o bibliotecário Calímaco, cuja produção epigramática é satisfatoriamente conhecida, mas de quem se ignora a forma como produziu seus livros elegíacos mais extensos, tais como o Hécale e as Origens, e que é valorado por Quintiliano (Inst. Or. X 1, 58) como príncipe da elegia.

Nesses termos, é relevante considerar que, embora seja possível relacionar o uso da matéria erótica nos poemas elegíacos a Euforião de Cálcis, remetendo-a ao século III a.C., a compreensão da distinção entre elegia erótica e epigrama erótico parece ser posterior aos poetas do principado. Em Quintiliano, Calímaco é o primeiro da elegia (Inst. Or. X 1, 58: elegiam... cuius princeps habetur Callimachus), em nítido contraste com Marcial (IV 23), que coloca Calímaco como detentor da palma no epigrama. Ao mesmo tempo, o termo elegia erótica parece não encontrar uso anterior ao de Aulo Gélio (XIX 9, 4), no século II d.C., portanto.

Dessa advertência, pode-se concluir que o livro elegíaco de Galo, em que o fragmento em discussão poderia ter estado incluído, foi provavelmente diferente do que se espera ao ler os poetas elegíacos, seus seguidores, que escreveram durante o principado de Augusto, nas últimas décadas do século I a.C. Essa mesma concepção, aliás, vale para a análise de Catulo, cuja obra chegou ao nosso tempo em forma de coletânea, agrupada por determinados atributos que podem não ter sido contemplados numa edição anterior - como dizemos modernamente, "fiel” às determinações do autor. Nesse sentido, um e outro autor podem ter produzido peças elegíacas majoritariamente breves ou longas, mas serão citados pelos poetas elegíacos em função de sua matéria amorosa, não da extensão de seus poemas, ${ }^{17}$ aspecto que importará mais para os autores do fim do século I d.C. Há a possibilidade, inclusive, de que o livro elegíaco de Galo fosse mais semelhante a um epigrammaton liber de Marcial que ao livro de Propércio.

\section{Uma proposta de tradução poética}

Embora o aparentemente exíguo trabalho braçal possa fazer a tradução de um fragmento como este parecer fácil, a tarefa de apresentar os versos de Galo em forma poética é árdua. O primeiro desafio é externo: para escolher os parâmetros de

\footnotetext{
${ }^{17}$ A esse respeito, historiamos semelhante leitura, para os epigramas de Catulo, no capítulo "Catulo em Marcial”, de nossa dissertação de mestrado (Cairolli, op. cit., p. 66-104).
} 


\section{nuntius antiquus}

abordagem ao texto, muitas vezes é salutar considerar o sistema em que o poema está inserido, o que, para os únicos nove versos sobreviventes de um autor de mérito reconhecido por seus sucessores, do qual se esperam ao menos quatro livros, passa por fazer opções teóricas contestáveis e que, além disso, poderão ser risíveis diante de uma descoberta mais abrangente a fazer no futuro. A esse se somam os desafios internos: de que forma abordar as lacunas dos versos? Com que autores confrontar o léxico? Que tradição tradutológica melhor se aplicará aos referidos versos? A análise que acima fizemos ajuda a responder essas perguntas.

Da leitura acima proposta assumimos que os poemas sobreviventes de Galo (e possivelmente outros que estavam no mesmo rolo) pertencem ao gênero epigramático. Com isso, aprofundamos a opção que ficou apenas sugerida por Anderson, Parson e Nisbet, que se encarregaram da primeira publicação, em 1978, e se referem aos poemas como epigrams, sem expor - diria até sem compreender - a implicação poética do termo, uma vez que ainda sustentam que o livro de Galo é um livro de Elegias.

Nesse sentido, nossa tradução tem como objetivo atender os seguintes parâmetros:

- Manutenção do calão, buscando eleger termos que correspondam ao campo semântico dos gêneros envolvidos (epigramático, mas também elegíaco);

- Atenção à disposição espacial das palavras no verso, aspecto que, aparentemente, era distintivo da poesia de Galo;

- Apresentação rítmica que soe familiar aos leitores de língua portuguesa, especialmente através do confronto de sistemas tradutológicos já experimentados em português na tradução de autores relacionados a Galo. Elegemos dispor o dístico elegíaco latino - estrutura sem equivalente em português - em dísticos compostos de um verso dodecassílabo seguido de um verso decassílabo. Do ponto de vista rítmico, essa estrutura tenta ecoar a disparidade rítmica que o dístico elegíaco possuía em latim. Do ponto de vista elocutivo, aproveita os dois versos mais tradicionalmente usados no vernáculo para a produção de poesia "erudita" (essa definição está baseada no confronto entre o tipo de poesia produzido com esses versos e a poesia produzida nas medidas mais curtas, chamadas redondilhas maior e menor. Tradicionalmente utilizada para distinguir as poesias camonianas, tal distinção baseada nos metros poderá ser verificada em diversos autores que produzem poesia em língua portuguesa, como Gregório de Matos e Bocage), utilizando-os para produzir um gênero de poesia que, embora 


\title{
nuntius antiquus
}

caracterizado pela matéria baixa, era douto do ponto de vista rítmico. Do ponto de vista tradutológico, essa escolha segue a opção rítmica utilizada por diversos tradutores de poesia elegíaca e epigramática: vemo-lo na tradução de Catulo por João Angelo Oliva Neto, na Priapeia do mesmo tradutor, nas investidas em Ovídio de Brunno Vinícius Gonçalves Vieira, nas traduções de Marcial de Robson Tadeu Cesila e no Propércio de Guilherme Gontijo Flores. Mais, essa eleição incorpora a experiência que adquirimos com a tradução dos epigramas de Marcial que empreendemos em nossa dissertação experiência que também pode ser apreciada nos epigramas VIII, 73 e VIII, 80 de Marcial, acima citados.

- Refletir a respeito das lacunas do papiro como parte do problema rítmico e semântico.

Eis os resultados obtidos:

\section{Fragmento 1}

\author{
tristia nequit[ia ....] ] Lycori tua \\ Co’as] malícias, Licóris, tuas tristes.
}

Nossa eleição pela disposição irregular, bem como pela colocação de co'as no espaço da lacuna está baseada na prudência em relação à leitura de nequitia, que, no dizer de Anderson, "se encaixa na desaprovação de uma amante de quem se esperou algo melhor". ${ }^{18}$ É irresistível pensar nessa relação, que casa com o discurso elegíaco, mas mesmo esses pesquisadores notam que a lacuna nos impede de assentar o sentido do verso. Nequitia poderia formar sintagma tanto com tua, quanto com tristia, ou mesmo com ambos, conforme o que houvesse na lacuna e nos versos anteriores. Isolar como parte da lacuna o termo que traduz o caso ablativo para o português (co'as) visa a "enfraquecer" as relações sintáticas entre as demais palavras, levando-as a nível similar ao que o latim apresenta.

\section{Fragmento 2}

\footnotetext{
${ }^{18}$ Cf. Anderson, op. cit., p. 140: Suits reproaches to a mistress of whom better things might have been expected.
} 
Fata mihi, Caesar, tum erunt mea dulcia, quom tu maxima Romanae pars eri $<s>$ historiae, postque tuum reditum multorum templa deorum fixa legam spolieis deiuitiora tueis.

Meu fado, César, doce será quando fores a maior parte da romana história e eu ler, co'a tua volta, que os templos dos deuses são mais ricos co’o espólio que votaste.

Duas passagens do texto latino tiveram particular atenção em nossa tradução, a saber, quom tu ("quando tu" - v. 1) e fixa legam ("lerei que estão pendurados" - v. 4), que, pela forma como foram dispostas, têm espacial ênfase no poema. No primeiro verso do latim, a colocação de $t u$ na última posição do verso acentua o sentido de que César em pessoa será a alegria de Galo; no quarto verso, a posição inicial de fixa legam coloca-os no centro da sentença: a segunda causa da felicidade de Galo não será o espólio, mas sim ler que o espólio foi pendurado nas paredes do templo - prática cuja descrição mais conhecida, em poesia, é de Horácio, Odes I 5, pendurando as vestes úmidas no templo de Netuno por sobreviver ao naufrágio de um amor pérfido. Manter tu como última palavra do primeiro verso era imprescindível, solução que atendemos, cremos, apenas parcialmente com a transferência, na tradução de "fores" (eri<s>) para essa posição, com o que se tornou mais sentencioso o verso seguinte. Tentou-se manter a ênfase da palavra fixa traduzindo-a, de forma mais livre, por "votaste", e posicionando-a ao fim do verso. Essa opção, sobrepondo os sentidos de "pendurar" e "votar os espólios", perde-se por declarar o que está velado no texto, ganha por oferecer ao leitor português não familiarizado um termo de mais fácil compreensão, sem, contudo, trair a precisão histórica que pretende o leitor estudioso.

\section{Fragmento 3}

..... . .... tandem fecerunt c[ar]mina Musae quae possim domina deicere digna mea.

.......... J. atur idem tibi, non ego, Visce

. . . ...... l. Kato, iudice te uereor.

......... ] enfim, as Musas fizeram canções

que eu possa depor, dignas da senhora.

. . . . . . ado ad contigo o mesmo, Visco, eu não

......... ] temo, Catão, o teu juízo. 


\section{nuntius antiquus}

A principal preocupação dessa tradução foi a forma de incluir as lacunas aos sentidos possíveis e à metrificação. A primeira precaução foi que o ritmo dos três versos mutilados, escandidos do fim para o começo, fosse compatível aos versos portugueses e que sobrassem sílabas poéticas, de modo a que a tradução representasse efetivamente um fragmento de poesia. Desta forma, no verso 1, "enfim” começa na terceira sílaba poética; na mesma sílaba começa "temo", no verso 4, formando estes versos, respectivamente, um dodecassílabo e um decassílabo mutilados no início. O mesmo princípio foi levado em conta para o verso 3, acrescentando-se, dentro da lacuna, a terminação de particípio -ado, que tenta ser equivalente, de alguma forma, à palavra mutilada no verso latino ]atur, sufixo de um verbo na terceira pessoa do singular na voz passiva ou de verbo depoente. A eufonia em português motivou que traduzíssemos tibi por "contigo", em lugar de "a ti" ou "para ti" que seriam mais precisos.

\section{Conclusão}

Temos visto até aqui algumas das leituras que os antigos empreenderam em relação à poesia de Cornélio Galo, bem como algumas interpretações que pesquisadores contemporâneos fizeram dos nove versos há pouco escavados no Egito. No que toca ao parecer dos antigos, poucos julgamentos podem ser feitos, porquanto não conhecemos o teor da obra a que tiveram acesso. Quanto ao parecer dos contemporâneos, nota-se que sua crítica se vincula ora a uma, ora a outra parte dos juízos antigos. Fairweather ${ }^{19}$ propõe que os versos pertencem ao gênero bucólico, em particular aos duelos entre poetas pastores (os cantos amebeus), vinculando-se talvez aos juízos de Sérvio, gramático do século V que aponta a filiação das Bucólicas de Virgílio aos poemas de Galo. Anderson ${ }^{20}$ et alii, que escavaram os fragmentos, surpreendem-se em encontrar tantos epigramas seguidos em um livro de elegias. Com isso, assumem perigosamente que, quando Sérvio diz que Galo escreveu elegos, se referia a livros nomeadamente elegíacos e não a coleções de poemas em metro elegíaco, os quais tanto podiam ser epigramas quanto elegias.

Os gêneros epigramático e elegíaco, além do metro, compartilham também alguns temas, tais como os dissabores das relações amorosas, embora os tratem de maneiras diferentes. Nesse sentido, a leitura de um poeta epigramático anterior, como

\footnotetext{
${ }^{19}$ Cf. Anderson, op. cit., p. 167.

${ }^{20}$ Cf. Anderson, op. cit., p. 149.
} 
Catulo, e um posterior, como Marcial, demonstra que os poemas de Galo, "estranhos" para a elegia, estão em conformidade com gênero epigramático. Desta forma, seus livros (se os versos aqui discutidos não procederem de uma coletânea ou de outra forma de circulação) podiam diferir uns dos outros ou podiam se organizar de forma mais flexível que os livros de elegias do principado de Augusto, se é que, de alguma forma, possuíam espécimes de elegias e não majoritariamente epigramas.

\section{Referências}

ANDERSON, R. D.; NISBET, R. G. M.; PARSONS, P. J. Elegiacs by Gallus from Qasr Ibrim. Journal of Roman Studies. Cambridge, vol. LXIX, p. 125-155, 1979.

AUGUSTO. A Caesaris Augusti Imperatoris Operum Fragmenta. Iteratis curis collegit, recensuit H. Malcovati. Torino: Paravia, 1927.

CAIROLLI, F. Pequena gramática poética de Marcial. Dissertação de mestrado inédita. São Paulo: DLCV/ FFLCH-USP, 2009.

CATULO. O Livro de Catulo. Tradução, introdução e notas de João Angelo Oliva Neto. São Paulo: Edusp, 1996.

CESILA, R. O palimpsesto epigramático de Marcial: intertextualidade e geração de sentidos na obra do poeta de Bílbilis. Tese de doutorado inédita. Campinas: IELUNICAMP, 2008.

DÍON CÁSSIO. Dio's Roman history. With an English translation by Earnest Cary on the basis of the version of Herbert Baldwin Foster. IX vols. London/ New York: Heinemann/ MacMillan, 1914-1927.

FAIRWEATHER, J. The "Gallus Papyrus": a new interpretation. The Classical Quarterly. Cambridge, vol. XXXIV, n. 1, p. 167-174, 1984.

FLORES, G. A diversão tradutória: uma tradução das Elegias de Sexto Propércio. Dissertação de mestrado inédita. Belo Horizonte: FALE-UFMG, 2008.

GÉLIO, A. The Attic nights of Aulus Gellius. With an English translation by John C. Rolfe, Ph.D., Litt.D. Cambridge/ London: Harvard University Press, 1984. Vol. I.

GENTILI, B. Epigramma ed elegia. In: DIHLE, A. (org). L'Épigramme grecque. Entretiens sur Antiquité classique. Genève: Vandroevres, 1968. Tome XIV, p. 39-70. 
MARCIAL. Epigrammata. Recognouit breuique adnotatione critica instruxit W. M. Lindsay. Oxford: Clarendon Press, 1987.

OLIVA NETO, J. A. Falo no jardim. Priapeia grega e latina. Cotia/ Campinas: Ateliê Editorial/ UNICAMP, 2006.

OVÍDIO. Amores; Medicamina; Faciei; Feminae; Ars Amatoria; Remedia Amoris. Oxford: Clarendon Press, 1990.

1967-1977.

. Tristia. Ed. Georg Luck. 2 vols. Heidelberg: C. Winter Universitatsverlag,

PROPÉRCIO. Elegies. Cambridge/ London: Harvard University Press, 1952.

PUTNAM. M. Propertius and the Gallus Fragment. Zeitschrift für Papyrologie und Epigraphik. Bonn, Bd. XXXIX, p. 49-56, 1980.

QUINTILIANO. M. Fabii Quintiliani Institutionis Oratoriae. Cambridge/ London: Harvard University Press, 1989.

SÉRVIO. Servii Grammatici qui feruntur in Vergilii carmina commentarii. Recensuerunt Georg Thilo et Hermann Hagen. 3 vols. Leipzig: Teubner, 1887.

SICKLE, J. Poetics of opening and closure in Meleager, Catullus, and Gallus. The Classical World. New York, vol. LXXV, n. 2, p. 65-75, nov. - dec., 1981.

SOMMERVILLE, T. The literary merit of the new Gallus. Classical Philology. Chicago, vol. CIV, n.1, p. 106-113, 2009.

SUETÔNIO. A vida dos doze Césares. Tradução de Sady Garibaldi. São Paulo: Ediouro, 2002.

VEYNE, P. (org.). História da vida privada. Vol. I: do Império Romano ao ano mil. Trad. Hildegard Feist. São Paulo: Companhia das Letras, 2009, p. 93-111.

VIEIRA, B. V. G., O dístico elegíaco em português: tradução de Ovídio, Amores, I, 1, 4, 5, 9. Revista Eletrônica Antiguidade Clássica. Rio de Janeiro, n. 2, p. 26-37, II semestre de 2008. 